\title{
Sugarbaker procedure for Pseudomyxoma Peritonei
}

\author{
A. H. Mirnezami · B. J. Moran · T. D. Cecil
}

Published online: 19 August 2009

(C) Springer-Verlag 2009

Pseudomyxoma Peritonei (PMP) is an uncommon condition characterised by diffuse mucinous ascites or "jelly belly", and multifocal peritoneal implants. PMP commonly arises from an occult epithelial malignancy of the appendix. Surgical treatment involves a series of peritonectomy procedures and visceral resections to achieve macroscopic tumour clearance followed by heated intraperitoneal chemotherapy as described by Sugarbaker (Figs. 1, 2, 3, 4, 5, 6, 7, 8, 9).
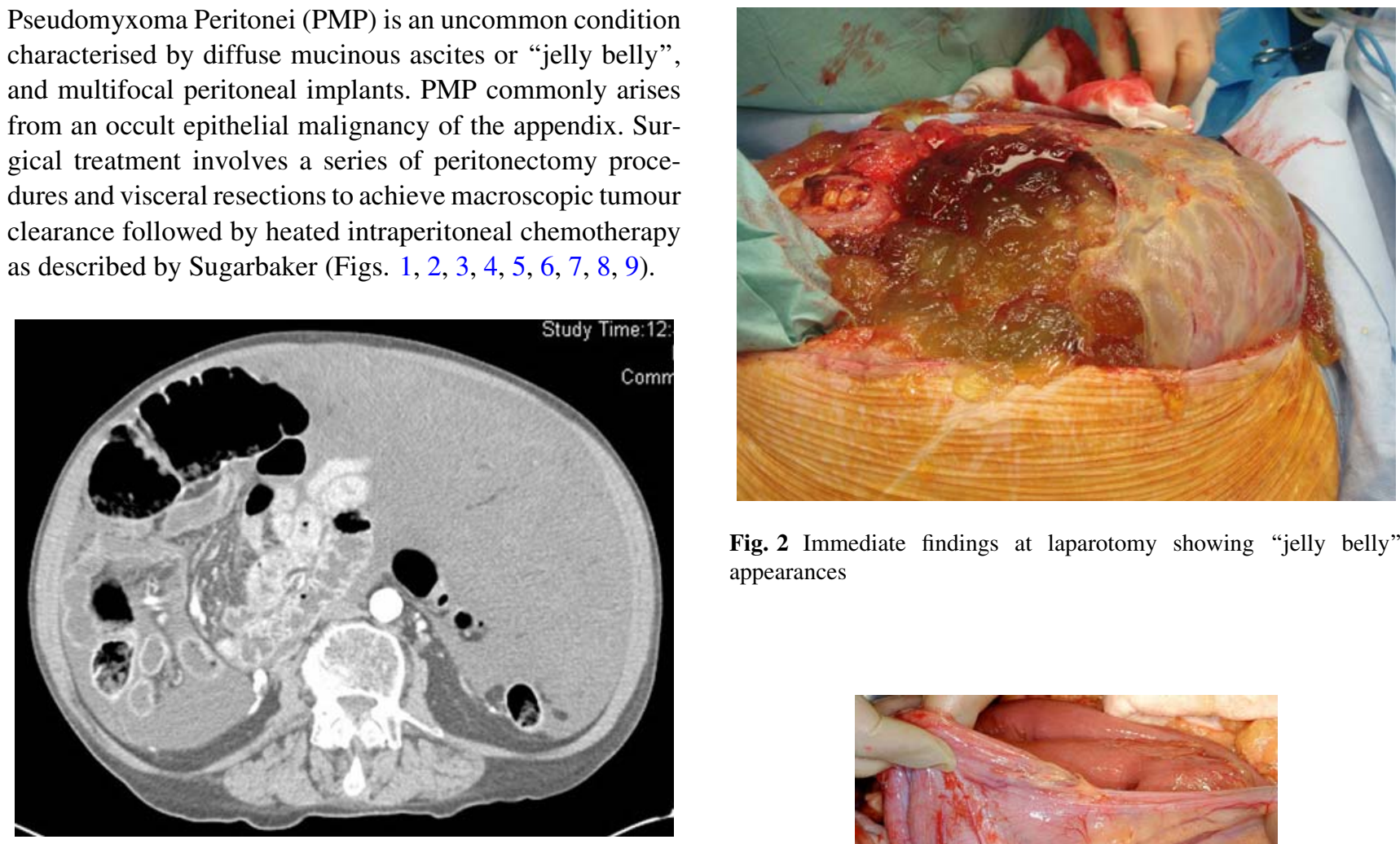

Fig. 2 Immediate findings at laparotomy showing "jelly belly" appearances

Fig. 1 Preoperative cross-sectional imaging showing diffuse intraperitoneal involvement with mucinous ascites

\section{A. H. Mirnezami $(\square)$}

University Surgical Unit, Southampton General Hospital,

Tremona road, Southampton SO16 6YD, UK

e-mail: A.H.Mirnezami@ soton.ac.uk

\section{B. J. Moran - T. D. Cecil}

National Pseudomyxoma Peritonei Centre, Basingstoke and North Hampshire Hospital, Basingstoke RG24 9NA, UK e-mail: brendan.moran@nht.nhs.uk

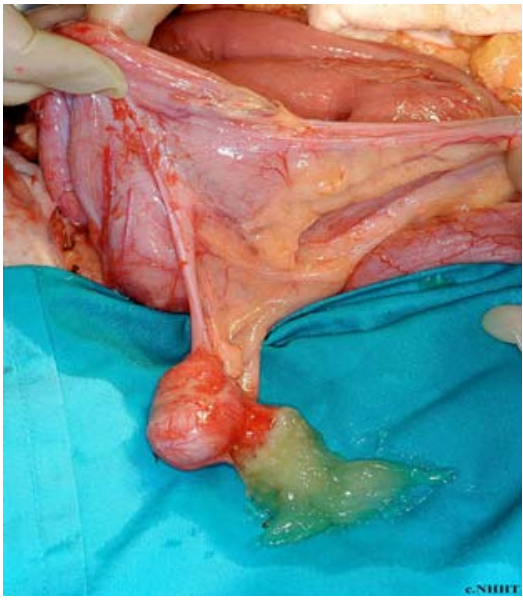

Fig. 3 Perforated primary appendiceal tumour 


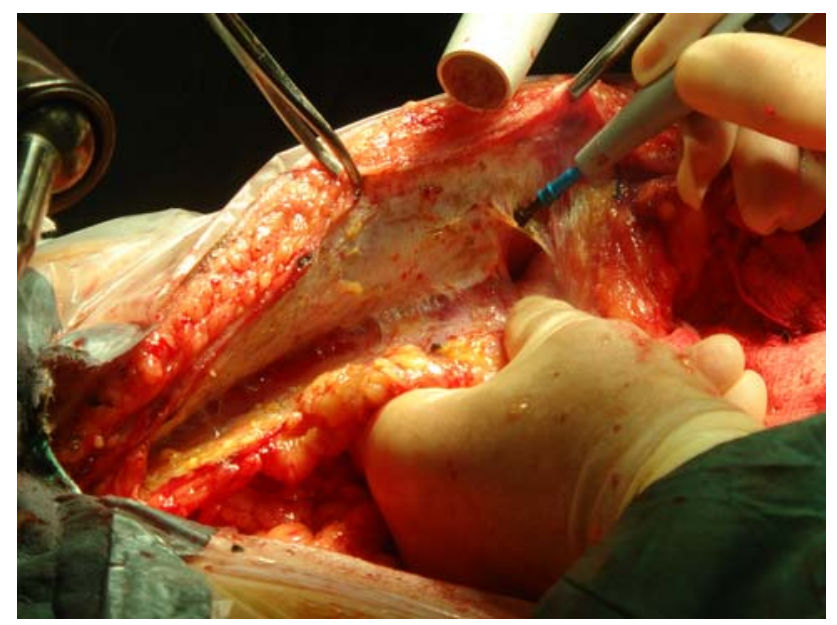

Fig. 4 Right parietal peritonectomy

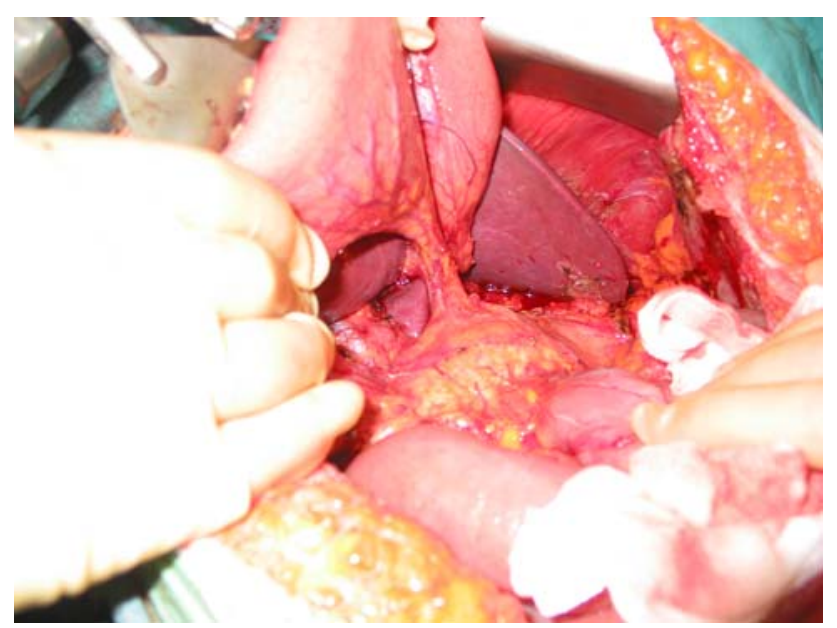

Fig. 5 Stomach reflected upwards after greater and lesser omentectomy and splenectomy with left gastric artery preserved

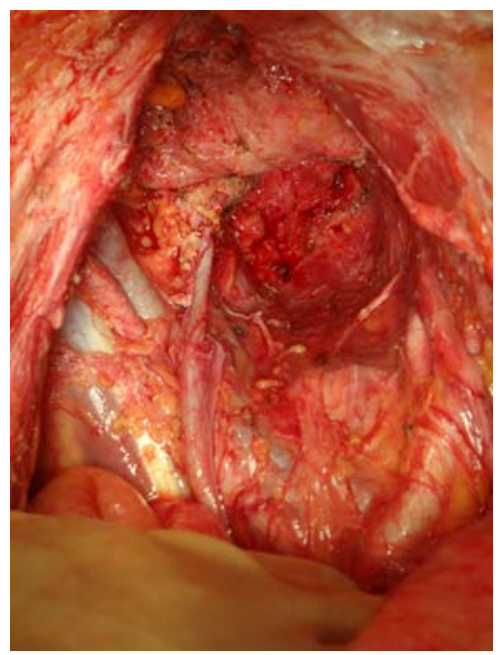

Fig. 6 Pelvic peritonectomy and anterior resection with bladder stripped of peritoneum and retracted forward

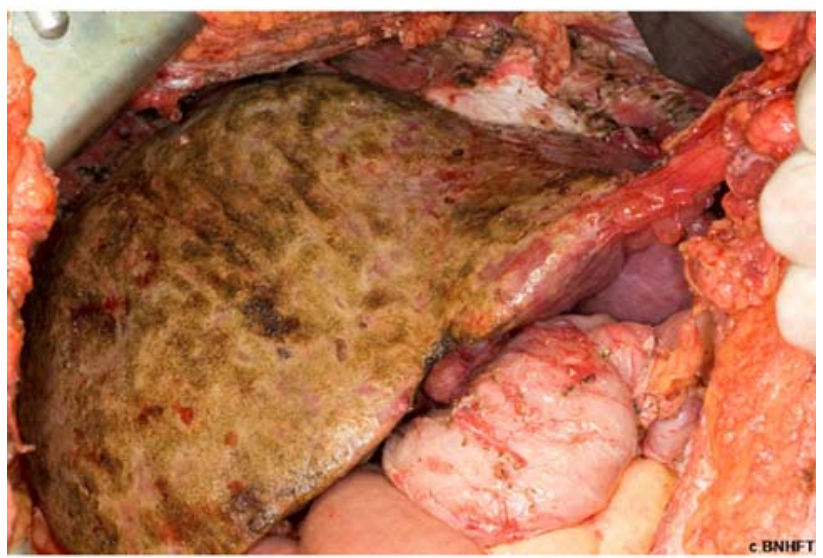

Fig. 7 Liver capsulectomy with high power diathermy, and cholecystectomy

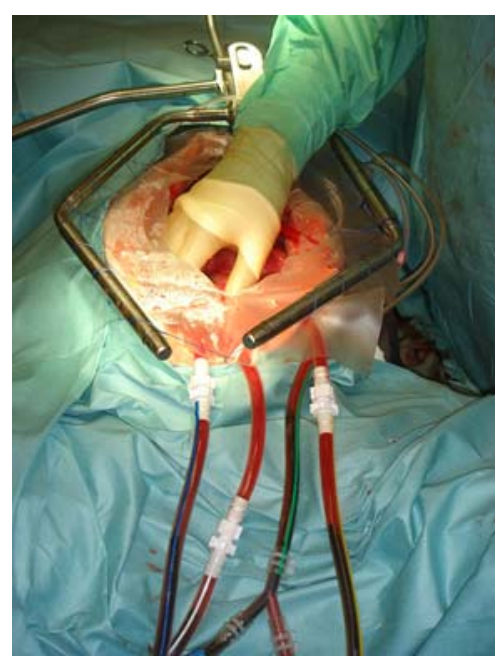

Fig. 8 Heated intraoperative peritoneal chemotherapy with mitomycin $\mathrm{C}$ at $41^{\circ} \mathrm{C}$ by coliseum technique

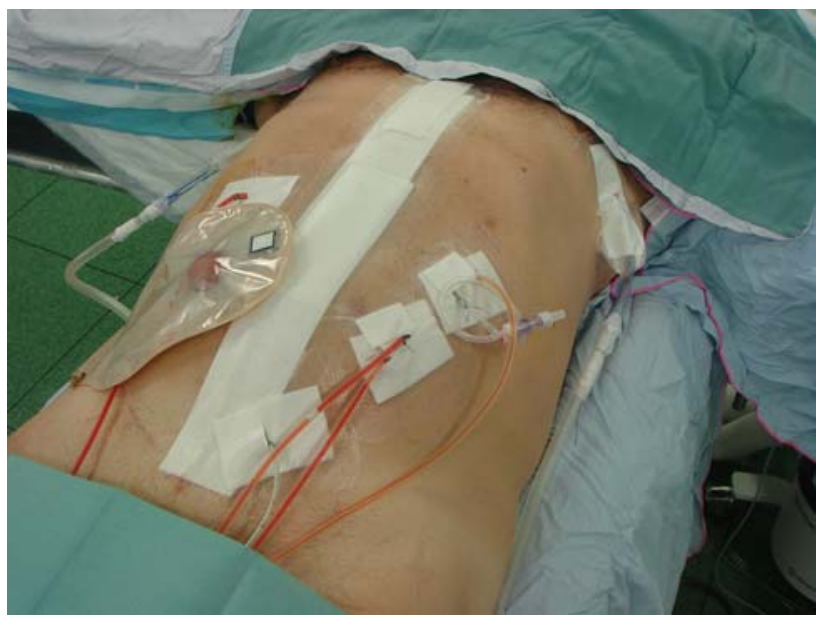

Fig. 9 Flat abdomen following complete cytoreduction with tube drains for postoperative intraperitoneal chemotherapy with 5fluorouracil 